\title{
Decline in semen quality among infertile men in Brazil during the past 10 years
}

\author{
Edson Borges Jr. ${ }^{1,2}$, Amanda Souza Setti 1,2, Daniela Paes de Almeida Ferreira Braga ${ }^{1,2}$, Rita de Cassia Savio \\ Figueira ${ }^{1}$, Assumpto laconelli Jr. ${ }^{1,2}$ \\ ${ }^{1}$ Fertility, Centro de Fertilização Assistida, São Paulo, Brasil; ${ }^{2}$ Instituto Sapientiae, Centro de Estudos e \\ Pesquisa em Reprodução Humana Assistida, São Paulo, Brasil
}

\section{ABSTRACT}

Purpose: To investigate whether the semen quality of men undergoing conventional semen analysis is deteriorating over time.

Materials and Methods: We analyzed and compared the sperm count, motility and morphology of 2300 semen samples provided by males undergoing conventional seminal analysis, from years 2000 to 2002 and 2010 to 2012. The incidences of severe oligozoospermia and azoospermia over time were also compared.

Results: A total of 764 sperm samples were analyzed in 2000-2002 and 1536 in 20102012. Over time, the mean sperm concentration/ml decreased significantly from 61.7 million in 2000-2002 to 26.7 million in 2010-2012 ( $R 2=11.4 \%, p<0.001)$, the total sperm concentration decreased significantly from 183.0 million to 82.8 million ( $R 2=11.3 \%$, $\mathrm{p}<0.001$ ), and the percentage of normal forms decreased significantly from $4.6 \%$ to $2.7 \%(\mathrm{R} 2=9.8 \%, \mathrm{p}<0.001)$. The incidence of severe oligozoospermia significantly increased from 15.7\% to 30.3\% (OR: 1.09, p<0.001) and the incidence of azoospermia increased from 4.9\% to 8.5\% (OR: 1.06, $\mathrm{p}=0.001$ ).

Conclusions: This study demonstrated a significant time-related decline in semen quality of infertile patients. This finding might have implications on fertility and emphasizes the need for further studies addressing subject's life-style in order to find and reduce the causative agents. Future prospective and multicenter studies including representative samples of the general population are needed to confirm whether semen quality is really declining.

\section{ARTICLE INFO}

Key words:

Fertility; Spermatozoa; Sperm

Retrieval; Infertility

Int Braz J Urol. 2015; 41: 757-63

Submitted for publication:

April 14, 2014

Accepted after revision:

December 01, 2014

\section{INTRODUCTION}

During the past decades several studies have focused on the investigation of seminal quality. A meta-analysis of 61 studies found a significant global decline in the average sperm concentration from 113 to 66 million/ml among men with no history of infertility, between 1938 and 1991 (1). The results of this meta-analysis, showing that sperm density had declined globally by about 50\% during the second half of the last century, attracted significant attention and has been a matter of debate. Five years later, a reanalysis of 56 studies confirmed a significant decline in sperm density only in the United States and Europe (2). In an extended meta-analysis of 101 studies, Swan et al. (3) confirmed a decline in sperm density in the period from 1934 to 1996.

Since the publications of Carlson's meta-analysis several laboratories have analyzed their data retrospectively to study trends in their own country and an intense scientific debate 
was initiated. Despite some studies have suggested that there has been a decline in sperm quality (4-11) others found no significant decline in sperm quality over time (12-19) (reviewed by Jouannet et al. (20) and Merzenich et al. (21)).

A previous Brazilian study retrospectively investigated the quality of donated semen samples and a decline in both sperm count and normal sperm morphology was observed (8). To our knowledge, such an investigation has never been conducted in Brazilian sub fertile couples attending an assisted fertilization center for conventional semen analysis. Therefore, the objective of this study was to investigate if the seminal quality of men undergoing conventional semen analysis is deteriorating over time.

\section{MATERIALS AND METHODS}

\section{Experimental design}

This retrospective cohort study was performed in a private fertilization center. The sperm count, motility and morphology of 2300 semen samples originating from men undergoing conventional seminal analysis, from years 2000 to $2002(n=764)$ and 2010 to $2012(n=1536)$ were analyzed. The characteristics from semen samples collected from 2000-2002 were compared to those from samples collected from 2010-2012. The incidences of azoospermia and severe oligozoospermia (sperm concentration $<10 \times 10^{6} / \mathrm{ml}$ ) were compared between the groups.

A written informed consent was obtained, in which patients agreed to share the outcomes of their own exams for research purposes, and the study was approved by the local institutional review board.

\section{Semen collection and analysis}

All semen samples were collected in the laboratory. After liquefaction for 30 minutes, semen samples were evaluated for sperm count, motility and morphology. The volume of the ejaculate was determined by aspirating the liquefied sample into a graduated disposable pipette. Sperm counting and motility assessment were performed following the instructions of the counting chamber manufacturer (Makler counting chamber, Sefi
Medical Instruments, Haifa, Israel). The counting chamber was heated at $37^{\circ} \mathrm{C}$ in a heating stage prior to use. The sample was homogenized, by moving gently the container, and a volume of $3-5 \mu \mathrm{L}$ of semen sample was transferred to the center of the chamber. Sperm count was performed in 10 squares of the chamber. The total sperm count is the end concentration expressed as $10^{6}$ spermatozoa $/ \mathrm{ml}$. Sperm motility was assessed in 100 random spermatozoa by characterizing them as (i) grade A (rapid progressive motility), grade B (progressive motility), grade C (non progressive motility) and grade D (immotile) and the motility was expressed as percentage. Sperm morphology was evaluated on air-dried smears, fixed and stained by the quick-stain technique (Diff-Quick; Quick-Panoptic, Amposta, Spain). A total of 200 sperm cells were characterized as morphologically normal or abnormal and the final morphology was expressed as percentage.

\section{Statistical analysis}

Data were expressed as mean \pm standard deviation (SD) for continuous variables, and percentages were used for categorical variables. Mean values were compared by Student's t parametric test or Mann-Whitney non-parametric test. Percentages were compared by the Chi-squared or Fisher exact test, only when the expected frequency was five or lower. Linear regression analyses, adjusted for male age and period of abstinence, were used to investigate trends over time in sperm count, motility, and normal morphology, giving multiple coefficient of determination $\left(\mathrm{R}^{2}\right)$ for each model. Logistic regression, adjusted for male age and period of abstinence, was used to investigate trends over time in the incidence of severe oligozoospermia and azoospermia, giving odds ratios (ORs), with 95\% confidence intervals (CIs), as the effect estimates. A p value of $<0.05$ was considered statistically significant. Data analysis was conducted using MINITAB 16 Software.

\section{RESULTS}

A total of 764 sperm samples were analyzed in 2000-2002 and 1536 in 2010-2012. Mean male 
age was $35.7 \pm 7.8$ years. The general characteristics of sperm samples are shown in Table-1. The comparison of semen sample characteristics between the two groups is shown in Table-2 and Figure-1. Mean male age, days of abstinence and progressive sperm motility were similar between the 2000-2002 and 2010-2012 groups. Over time, the mean sperm concentration $/ \mathrm{ml}$ decreased significantly from 61.7 million in 2000-2002 to 26.7 million in 2010-2012 $\left(\mathrm{R}^{2}=11.4 \%, \mathrm{p}<0.001\right)$, the total sperm concentration decreased significantly from 183.0 million to 82.8 million $\left(\mathrm{R}^{2}=11.3 \%\right.$, $\mathrm{p}<0.001$ ), and the percentage of normal forms decreased significantly from $4.6 \%$ to $2.7 \%$ $\left(R^{2}=9.8 \%, p<0.001\right)$. The incidence of severe oligozoospermia significantly increased from 15.7\% to $30.3 \%$ (OR: $1.09, \mathrm{p}<0.001)$ and the incidence of azoospermia increased from $4.9 \%$ to $8.5 \%$ (OR: 1.06, $\mathrm{p}=0.001$ ) (Table-3).

\section{DISCUSSION}

Data presented in this study suggest that the semen quality of Brazilian sub fertile men seems to be deteriorating over time. Our results showed statistically significant differences in the seminal characteristics of the subjects analysed in the time gap of 10 years, i.e., 2000-2002 and 20102012 most notably in the sperm concentration and normal sperm morphology, favouring the period time of 2000-2002. It is important to highlight that during the study period, there were very little

Table 1 - General characteristics of analyzed semen samples $(n=2300)$.

\begin{tabular}{lcccc}
\hline Variable & Mean & SD & Min & Max \\
\hline Male age (y-old) & 35.7 & 7.8 & 15.0 & 71.0 \\
Days of abstinence & 4.2 & 2.8 & 0.0 & 30.0 \\
Semen sample volume (ml) & 3.3 & 1.7 & 0.1 & 11.3 \\
Sperm concentration/ml (million) & 38.3 & 46.7 & 0.0 & 540.0 \\
Total sperm concentration (million) & 116.0 & 143.0 & 0.0 & 984.0 \\
Progressive sperm motility (\%) & 36.9 & 18.9 & 0.0 & 84.0 \\
Sperm morphology & 3.4 & 2.9 & 0.0 & 16.0 \\
\hline
\end{tabular}

values are mean $\pm S D$, unless otherwise noticed. $\mathbf{S D}=$ standard deviation; $\mathbf{M i n}=$ minimum; $\mathbf{M a x}=$ maximum.

Table 2 - Comparison of semen sample characteristics between the groups.

\begin{tabular}{lccc}
\hline Variable & $\begin{array}{c}2000-2002 \\
(\mathrm{n}=764)\end{array}$ & $\begin{array}{c}2010-2012 \\
(\mathrm{n}=1536)\end{array}$ & $p$-value \\
\hline Male age (y-old) & $35.0 \pm 8.6$ & $35.3 \pm 8.1$ & 0.318 \\
Days of abstinence & $4.2 \pm 3.1$ & $4.2 \pm 2.7$ & 0.777 \\
Sperm sample volume (ml) & $3.4 \pm 1.8$ & $3.3 \pm 1.6$ & 0.473 \\
Sperm concentration/ml (million) & $61.7 \pm 69.4$ & $26.7 \pm 27.3$ & $<\mathbf{0 . 0 0 1}$ \\
Total sperm concentration (million) & $183.0 \pm 197.0$ & $82.8 \pm 89.5$ & $<\mathbf{0 . 0 0 1}$ \\
Progressive sperm motility (\%) & $36.4 \pm 18.3$ & $36.5 \pm 19.2$ & 0.812 \\
Normal morphology (\%) & 4.6 & 2.7 & $<\mathbf{0 . 0 0 1}$ \\
Incidence of severe oligozoospermia (\%) & $114 / 726(15.7)$ & $426 / 1405(30.3)$ & $<\mathbf{0 . 0 0 1}$ \\
Incidence of azoospermia (\%) & $38 / 764(4.9)$ & $131 / 1536(8.5)$ & $\mathbf{0 . 0 0 1}$ \\
\hline
\end{tabular}

values are mean $\pm S D$, unless otherwise noticed. SD: standard deviation. 
Figure 1 - Illustration of differences in semen characteristics.

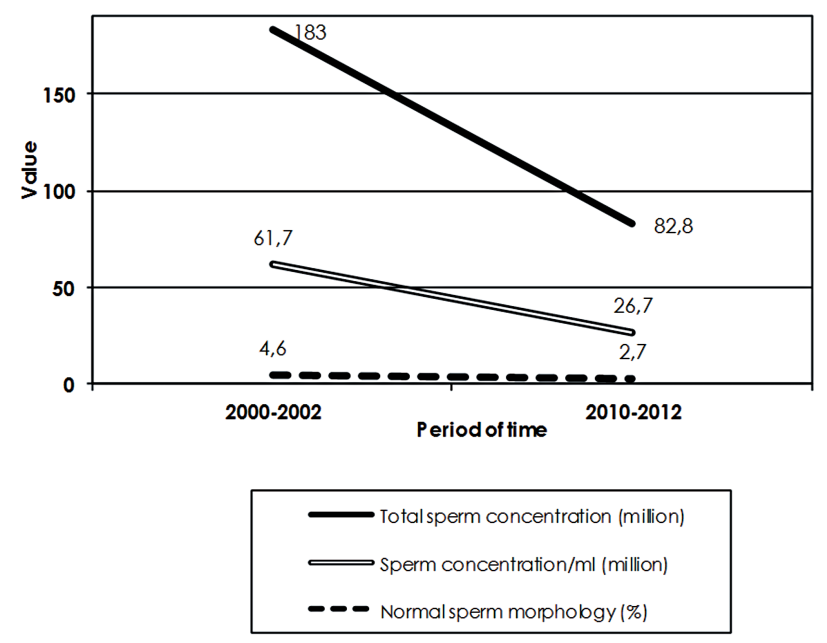

changes in the techniques and personnel involved in the analysis of semen. Technicians adhered to strict quality control and the equipment used were the same throughout the entire study period.

Our results support previous reports that the sperm quality in human semen seems to be globally declining. Glina et al. (8) found a decrease in sperm concentration in Brazilian donors samples from 1992 to 2003. This investigation was conducted in the same city as was the present study. Moreover, similar findings concerning sperm concentration have been reported in Spanish (9, 22), Scottish (6, 23), French (11, 24, 25), Norwegian $(26,27)$, Italian $(5,28,29)$, Danish (4, 30), Belgian (31), German (10), Austrian (32), Greek (33), Israeli $(34,35)$, Tunisian (36) Chinese (37) and Canadian (7) men. Conversely, many studies failed to demonstrate a time-related decline in semen quality (12-19, 38-41).

In the present study we also observed that sperm morphology has changed over time. This is in agreement with previous studies $(8,13,14$, $25,36)$. On the other hand, many studies failed to demonstrate such association $(22,32,42)$. It has been suggested that this parameter may vary over time depending on the classification criteria adopted and evaluation experience (13). In fact, in some studies the morphology was not investigated due to high inter-observer variation $(23,35)$.

Recently, a recent systematic review from Cocuzza and Esteves (43), concluded that there is no enough evidence confirming a global decline in semen parameters. Curiously, some studies observed that semen quality has not declined nor remained steady, but slightly increased in recent years $(15,42$, 44-47). Nevertheless, follow-up studies are necessary to investigate whether this finding is a real phenomenon or purely random variation. The discrepancy in the results obtained in the studies may be explained by selection criteria of volunteers or other confounding factors, such as the number of subjects included in each study. It is noteworthy that the observed time trend in semen quality might be an artifact, since the methodological variances amongst studies might be time-dependent (21).

The causes of the possible decreasing quality in male reproductive function remain to be elucidated. It has been suggested that the increased frequency of male reproductive abnormalities reflect adverse effects of environmental or lifestyle factors, such as occupational and environmental exposures, medications, and sexually transmitted diseases $(48,49)$. Indeed, the industrial

Table 3 - Regression analyses' results for trends over time in semen quality.

\begin{tabular}{lcc}
\hline Variable & $\mathrm{R}^{2}(\%)$ & $\mathrm{p}$ value \\
\hline Sperm concentration/ml & 11.4 & $<0.001$ \\
Total sperm concentration & 11.3 & $<0.001$ \\
Normal forms & 9.8 & $<0.001$ \\
Variable & $\mathbf{O R}(\mathbf{C l})$ & $\mathbf{p}$ value \\
Severe oligozoospermia & $1.09(1.06-1.11)$ & $<0.001$ \\
Azoospermia & $1.06(1.02-1.10)$ & 0.001 \\
\hline
\end{tabular}


expansion and demanding agricultural activity of South America, along with repeated disrespect for environmental protection measures, are a risk to human populations health (50). However, a recent systematic review reported that there is no scientific evidence of a causative role for endocrine disruptors in the decline of semen quality (43).

Poor semen quality appears to be a common occurrence that is in agreement with the growing need of assisted reproduction worldwide (21). In the present study we observed an increase in the incidence of severe oligozoospermia, which is in line with the observed decline in sperm count, and azoospermia. It is known that azoospermia is common among the infertile population and it has been suggested that its prevalence is likely to increase in infertility clinics (51). Many patients with azoospermia are thought to have a contributing genetic cause. Therefore, there is a concern regarding the risk of transmission of these abnormalities to offspring (52).

The potential drawbacks of this study are: (i) semen analysis data were retrospectively reviewed; and therefore, (ii) we were unable to collect information on potential confounders, including occupation of the subjects, smoking, food habits and level of stress. Moreover, (iii) the inclusion of potential sub fertile men attending an infertility center might be a selection bias.

As suggested by Olsen and Rachootin (53), a monitoring system could ensure that we have a better understanding of developments over the next years. One of the consequences of a possible decline in sperm quality is the increase of infertile couples (50).

\section{CONCLUSIONS}

This study demonstrated a significant time-related decline in semen quality of infertile patients. This finding might have implications on fertility and emphasizes the need for further studies addressing subject's life-style in order to find and reduce the causative agents. Future prospective and multicenter studies including representative samples of the general population are needed to confirm whether semen quality is really declining.

\section{CONFLICT OF INTEREST}

None declared.

\section{REFERENCES}

1. Carlsen E, Giwercman A, Keiding N, Skakkebaek NE. Evidence for decreasing quality of semen during past 50 years. BMJ.1992;305:609-13.

2. Swan SH, Elkin EP, Fenster L. Have sperm densities declined? A reanalysis of global trend data. Environ Health Perspect.1997;105:1228-32.

3. Swan SH, Elkin EP, Fenster L. The question of declining sperm density revisited: an analysis of 101 studies published 1934-1996. Environ Health Perspect.2000;108:961-6.

4. Bonde JP, Kold Jensen T, Brixen Larsen S, Abell A, Scheike $\mathrm{T}$, Hjollund $\mathrm{NH}$, et al. Year of birth and sperm count in 10 Danish occupational studies. Scand J Work Environ Health.1998;24:407-13.

5. Bilotta P, Guglielmo R, Steffè M. [Analysis of decline in seminal fluid in the Italian population during the past 15 years]. Minerva Ginecol.1999;51:223-31.

6. Irvine S, Cawood E, Richardson D, MacDonald E, Aitken J. Evidence of deteriorating semen quality in the United Kingdom: birth cohort study in 577 men in Scotland over 11 years. BMJ.1996;312:467-71.

7. Younglai EV, Collins JA, Foster WG. Canadian semen quality: an analysis of sperm density among eleven academic fertility centers. Fertil Steril.1998;70:76-80.

8. Glina S, Nova T, Brand VBF, et al. Avaliação dos parâmetros seminais em doadores de sêmen no período de dez anos na cidade de São Paulo. Einstein.2010;8:423-9.

9. Fernandez MF, Duran I, Olea N, Avivar C, Vierula M, Toppari $\mathrm{J}$, et al. Semen quality and reproductive hormone levels in men from Southern Spain. Int J Androl.2012;35:1-10.

10. Paasch U, Salzbrunn A, Glander HJ, Plambeck K, Salzbrunn $\mathrm{H}$, Grunewald S, et al. Semen quality in sub-fertile range for a significant proportion of young men from the general German population: a co-ordinated, controlled study of 791 men from Hamburg and Leipzig. Int J Androl.2008;31:93-102.

11. Auger J, Jouannet P. Evidence for regional differences of semen quality among fertile French men. Fédération Francaise des Centres d'Etude et de Conservation des Oeufs et du Sperme humains. Hum Reprod.1997;12:740-5.

12. Acacio BD, Gottfried T, Israel R, Sokol RZ. Evaluation of a large cohort of men presenting for a screening semen analysis. Fertil Steril. 2000;73:595-7.

13. Andolz P, Bielsa MA, Vila J. Evolution of semen quality in North-eastern Spain: a study in 22,759 infertile men over a 36 year period. Hum Reprod.1999;14:731-5. 
14. Benshushan A, Shoshani O, Paltiel O, Schenker JG, Lewin A. Is there really a decrease in sperm parameters among healthy young men? A survey of sperm donations during 15 years. J Assist Reprod Genet.1997;14:347-53.

15. Berling $\mathrm{S}$, Wölner-Hanssen P. No evidence of deteriorating semen quality among men in infertile relationships during the last decade: a study of males from Southern Sweden. Hum Reprod.1997;12:1002-5.

16. Itoh N, Kayama F, Tatsuki TJ, Tsukamoto T. Have sperm counts deteriorated over the past 20 years in healthy, young Japanese men? Results from the Sapporo area. J Androl.2001;22:40-4.

17. Zheng $\mathrm{Y}$, Bonde JP, Ernst E, Mortensen JT, Egense J. Is semen quality related to the year of birth among Danish infertility clients? Int J Epidemiol.1997;26:1289-97.

18. Vierula M, Niemi M, Keiski A, Saaranen M, Saarikoski S, Suominen J. High and unchanged sperm counts of Finnish men. Int J Androl.1996;19:11-7.

19. Marimuthu P, Kapilashrami MC, Misro MM, Singh G. Evaluation of trend in semen analysis for 11 years in subjects attending a fertility clinic in India. Asian $\mathrm{J}$ Androl.2003;5:221-5.

20. Jouannet $P$, Wang $C$, Eustache $F$, Kold-Jensen T, Auger $J$. Semen quality and male reproductive health: the controversy about human sperm concentration decline. APMIS.2001;109:333-44.

21. Merzenich H, Zeeb H, Blettner M. Decreasing sperm quality: a global problem? BMC Public Health.2010;10:24.

22. Mendiola J, Jørgensen N, Mínguez-Alarcón L, Sarabia-Cos L, López-Espín JJ, Vivero-Salmerón G, et al. Sperm counts may have declined in young university students in Southern Spain. Andrology.2013;1:408-13.

23. Sripada S, Fonseca S, Lee A, Harrild K, Giannaris D, Mathers $E$, et al. Trends in semen parameters in the northeast of Scotland. J Androl.2007;28:313-9.

24. De Mouzon J, Thonneau P, Spira A, Multigner L. Declining sperm count. Semen quality has declined among men born in France since 1950. BMJ.1996;313:43; author reply 44-5.

25. Geoffroy-Siraudin C, Loundou AD, Romain F, Achard V, Courbière $B$, Perrard $M H$, et al. Decline of semen quality among 10932 males Consulting for couple infertility over a 20-year period in Marseille, France. Asian J Androl.2012;14:584-90.

26. Bendvold E. Semen quality in Norwegian men over a 20-year period. Int J Fertil.1989;34:401-4.

27. Ulstein M, Irgens A, Irgens LM. Secular trends in sperm variables for groups of men in fertile and infertile couples. Acta Obstet Gynecol Scand.1999;78:332-5.

28. Menchini-Fabris F, Rossi P, Palego P, Simi S, Turchi P. Declining sperm counts in Italy during the past 20 years. Andrologia.1996;28:304.
29. Vicari E, Conticello A, Battiato C, La Vignera S. [Sperm characteristics in fertile men and healthy men of the south-east Sicily from year 1982 to 1999]. Arch Ital Urol Androl.2003;75:28-34.

30. Bostofte E, Serup J, Rebbe H. Has the fertility of Danish men declined through the years in terms of semen quality? A comparison of semen qualities between 1952 and 1972. Int J Fertil.1983;28:91-5.

31. Van Waeleghem K, De Clercq N, Vermeulen L, Schoonjans F, Comhaire F. Deterioration of sperm quality in young healthy Belgian men. Hum Reprod.1996;11:325-9.

32. Lackner J, Schatzl G, Waldhör T, Resch K, Kratzik C, Marberger $M$. Constant decline in sperm concentration in infertile males in an urban population: experience over 18 years. Fertil Steril.2005;84:1657-61.

33. Adamopoulos DA, Pappa A, Nicopoulou S, Andreou E, Karamertzanis M, Michopoulos J, et al. Seminal volume and total sperm number trends in men attending subfertility clinics in the greater Athens area during the period 1977-1993. Hum Reprod.1996;11:1936-41.

34. Almagor M, Ivnitzki I, Yaffe H, Baras M. Changes in semen quality in Jerusalem between 1990 and 2000: a cross-sectional and longitudinal study. Arch Androl.2003;49:139-44.

35. Haimov-Kochman R, Har-Nir R, Ein-Mor E, Ben-Shoshan V, Greenfield C, Eldar I, et al. Is the quality of donated semen deteriorating? Findings from a 15 year longitudinal analysis of weekly sperm samples. Isr Med Assoc J.2012;14:372-7.

36. Feki NC, Abid N, Rebai A, Sellami A, Ayed BB, Guermazi $M$, et al. Semen quality decline among men in infertile relationships: experience over 12 years in the South of Tunisia. J Androl.2009;30:541-7.

37. Liang XW, Lu WH, Chen ZW, Wang XH, Zhao H, Zhang GY, et al. [Changes of semen parameters in Chinese fertile men in the past 25 years]. Zhonghua Nan Ke Xue.2008;14:775-8.

38. Axelsson J, Rylander L, Rignell-Hydbom A, Giwercman A. No secular trend over the last decade in sperm counts among Swedish men from the general population. Hum Reprod.2011;26:1012-6.

39. Esteves SC, Zini A, Aziz N, Alvarez JG, Sabanegh ES Jr, Agarwal A. Critical appraisal of World Health Organization's new reference values for human sêmen characteristics and effect on diagnosis and treatment of subfertile men. Urology.2012;79:16-22.

40. Mukhopadhyay D, Varghese AC, Pal M, Banerjee SK, Bhattacharyya AK, Sharma RK, et al. Semen quality and agespecific changes: a study between two decades on 3,729 male partners of couples with normal sperm count and attending an andrology laboratory for infertility-related problems in an Indian city. Fertil Steril.2010;93:2247-54.

41. Saidi JA, Chang DT, Goluboff ET, Bagiella E, Olsen G, Fisch H. Declining sperm counts in the United States? A critical review. J Urol.1999;161:460-2. 
42. Jørgensen N, Joensen UN, Jensen TK, Jensen MB, Almstrup $K$, Olesen IA, et al. Human sêmen quality in the new millennium: a prospective cross-sectional population-based study of 4867 men. BMJ Open.2012;2.

43. Cocuzza M, Esteves SC. Shedding light on the controversy surrounding the temporal decline in human sperm counts: a systematic review.ScientificWorldJournal.2014;2014:365691.

44. Carlsen E, Swan SH, Petersen JH, Skakkebaek NE. Longitudinal changes in semen parameters in young Danish men from the Copenhagen area. Hum Reprod.2005;20:942-9.

45. Fisch H, Goluboff ET, Olson JH, Feldshuh J, Broder SJ, Barad DH. Semen analyses in 1,283 men from the United States over a 25year period: no decline in quality. Fertil Steril.1996;65:1009-14.

46. Gyllenborg J, Skakkebaek NE, Nielsen NC, Keiding N, Giwercman A. Secular and seasonal changes in semen quality among young Danish men: a statistical analysis of semen samples from 1927 donor candidates during 1977-1995. Int J Androl.1999;22:28-36.

47. Jensen TK, Sobotka T, Hansen MA, Pedersen AT, Lutz W, Skakkebaek NE. Declining trends in conception rates in recent birth cohorts of native Danish women: a possible role of deteriorating male reproductive health. Int J Androl.2008;31:81-92.
48. Sharpe RM. Declining sperm counts in men-is there an endocrine cause? J Endocrinol.1993;136:357-60.

49. Forti G, Serio M. Male infertility: is its rising incidence due to better methods of detection or an increasing frequency? Hum Reprod.1993;8:1153-4.

50. Multigner L, Oliva A. Secular variations in sperm quality: fact or science fiction? Cad Saude Publica.2002;18:403-12.

51. Ezeh UI. Beyond the clinical classification of azoospermia: opinion. Hum Reprod.2000;15:2356-9.

52. Cocuzza M, Alvarenga C, Pagani R. The epidemiology and etiology of azoospermia. Clinics (Sao Paulo).2013;1:15-26.

53. Olsen J, Rachootin P. Invited commentary: monitoring fecundity over time-if we do it, then let's do it right. Am J Epidemiol.20035;157:94-7.

Correspondence address: Edson Borges Jr., MD, PhD Fertility,Centro de Fertilização Assistida Av. Brigadeiro Luis Antonio, 4545. São Paulo, SP, 01401-002, Brazil Telephone: +55 11 3018-8181

E-mail: edson@fertility.com.br 